\title{
Application Research on Drag Reduced Conductors for Electric Power Transmission Lines in Strong Wind Areas
}

\author{
Dong Qing Li ${ }^{1}{ }^{1}$, Zhen $\mathrm{Li}^{1}$, Zhen Liu ${ }^{1}$, Long Liu ${ }^{1}$, Chang Long Yang ${ }^{2}$, Wei Fan², Lu Yu Yang ${ }^{2}$ and Jia Jun $\mathrm{Si}^{1}$ \\ ${ }^{1}$ China Electric Power Research Institute, Beijing 102401, China \\ ${ }^{2}$ Electric Power Research Institute, State Grid Liaoning Electric Power Supply Co. Ltd., Shenyang 110006, China
}

\begin{abstract}
The breeze vibration duration of conductors is long, the vibration amplitude is strong and the frequency range is wide for electric power transmission lines in strong wind areas, which seriously affects the safe and stable operation of transmission lines. There are two design schemes of conductors which can achieve the purpose of reducing wind-induced disaster. One is enhancing the structural strength of conductors to withstand wind load, but the investment is enormous and the effect is limited. The other is developing drag reduced conductors to reduce wind load by changing conductor structure. This paper started from application feasibility analysis of drag reduced conductors and designed four drag reduced conductors by structure optimization of the conventional aluminium conductor steel reinforced JL/G1A-630/45-45/7, denoted as DFY630/45(45 $)$-R3.5, DFY630/45(60 $\left.{ }^{\circ}\right)-\mathrm{R} 3.5$, DFY630/45 $\left(45^{\circ}\right)-\mathrm{R} 3.2$ and DFY630/45 $\left(60^{\circ}\right)$-R3.2, respectively. The wind tunnel test was performed and the wind resistance coefficients in unit length of five conductors were compared. Result showed that the wind resistance coefficients in unit length of four drag reduced conductors were obviously lower than that of the conventional conductor. By controlling the manufacturing process, popularization and application of drag reduced conductors for transmission lines in strong wind areas can be realized.
\end{abstract}

\section{Introduction}

With the development of China's economy and the improvement of people's living standard, the power demand of whole society increases sharply. Since the energy bases are mostly located in the western region but the electric load centres are mainly concentrated in the eastern region, building power bases in the western region and transmitting power to the eastern region is an important channel for meeting power demand and resolving resource conflict. The north-western region in China, especially Xinjiang, Gansu and Ningxia Province belong to strong wind areas, the duration of strong wind is long and the wind speed is even and stable. Electric power transmission lines passing through the above areas will be greatly influenced by the strong wind climate. Under wind excitation conditions, different types of static or dynamic response will occur on the conductor [1]. Operation experience of current transmission lines indicates that the breeze vibration duration of conductors is longer, the vibration amplitude is stronger and the frequency range is wider under continuous strong wind conditions in the north-western region, which seriously affects the safe and stable operation of transmission lines and causes enormous economic losses.

Under strong wind conditions, enormous investment is often required to withstand wind load only by improving the structure strength of conductors, and the

\footnotetext{
${ }^{\mathrm{a} C o r r e s p o n d i n g ~ a u t h o r: ~ l i d o n g q i n g 1016 @ 163 . c o m ~(D . ~ L i) ~}$
}

effect has certain limitation. In contrast to this, developing drag reduced conductors based on structure optimization of conventional conductors is an effective way to realize wind load reduction. The popularization and application of drag reduced conductors in strong wind areas can substantially reduce the design load of conductor structure and consequently save the construction investment, which has significant economic benefit and brilliant application prospect.

\section{Application status of drag reduced conductors}

The drag reduced conductor is a dedicated conductor for overhead transmission lines which can reduce wind load when applied in strong wind areas. Based on comprehensive consideration of conductor structure and surrounded flow field, the characteristics of flow field can be changed by changing the conductor structure, and finally the reduction of wind load can be realized [2].

In the 1970s, researchers in Japan began to study the drag reduced conductors. Some test results were obtained, but associated achievements were rarely applied in practical engineering. From the 1990s, intensive study on drag reduced conductors was continuously performed by Japanese researchers, and obvious advancements were obtained in mechanism study of wind load reduction and practical application of drag reduced conductors [2]. In 
2006, the DR-HAL-type $820 \mathrm{~mm}^{2}$ drag reduced conductor manufactured by Japan Furukawa Electric Company was used in the $330 \mathrm{kV}$ transmission line constructed by Australia Western Power Company. In 2009, the DR-ACSR/AC-type $410 \mathrm{~mm}^{2}$ drag reduced conductor manufactured by Japan Furukawa Electric Company was used in the $275 \mathrm{kV}$ transmission line constructed by Japan Kansai Electric Power Company. In addition, the DR-ACSPUAC-type $680 \mathrm{~mm}^{2}$ drag reduced conductor manufactured by Japan Furukawa Electric Company will be used in the $154 \mathrm{kV}$ transmission line constructed by Japan Shikoku Electric Power Company.

In recent years, some domestic research institutes such as China Electric Power Research Institute and Jiangsu Zhongtian Technology Co. Ltd. also made an effort on the development of drag reduced conductors, but systematic study was lacked and products cannot be directly applied in practical engineering.

\section{Structure design of drag reduced conductors}

The reducing effect of wind load, the constructability and corona characteristics of conductors should be comprehensively considered during conductor design. Previous studies suggested that the aerodynamic drag coefficient corresponding to the critical Reynolds number of the conductor decreased with the increase of surface roughness of the conductor, and the wind load withstood by the conductor consequently decreased [3]. In addition, as compared to the conductor with round section, aerodynamic drag distribution along the conductor with elliptic section was uneven, which made the conductor have combined characteristics of low wind load and low noise [4]. Based on the above results, the drag reduced conductors were designed as follows at the early stage: one was that several wires with larger size were applied in the outer layer of the conductor to form protrusions and increase surface roughness. The other was that several wires with different section were applied in the outer layer of the conductor to obtain elliptic section. Wind tunnel test results showed that these two conductors had lower wind resistance coefficient in unit length than conventional conductors. However, there existed great difficulty during stringing construction process for these two conductors. When tension stringing was employed, the structure of conductors would be seriously destructed after passing through the pulley. Besides, the corona excitation voltage of these two conductors decreased sharply as compared to conventional conductors.

Based on the above analysis, a slotting way on the outside surface of the conductor with round section was employed for structure design to realize a good balance between reducing wind load and increasing construction difficulty as well as decreasing corona excitation voltage. Table 1 lists main technical parameters of the conventional aluminium conductor steel reinforced JL/G1A-630/45-45/7. Fig. 1 shows the schematic sections of the conventional conductor and four designed drag reduced conductors, denoted as DFY630/45(45 $)$-R3.5,

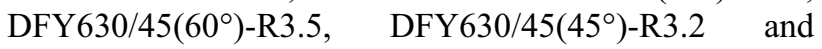

DFY630/45(60)-R3.2, respectively. As compared to the conventional conductor, shaped wires were applied in the outer layer of drag reduced conductors instead of round wires, and the outside surface was slotted. For four drag reduced conductors, the open-angle and arc radius of the outside surface were different from each other.

Table 1. Main technical parameters of conventional aluminium conductor steel reinforced JL/G1A-630/45-45/7.

\begin{tabular}{|c|c|}
\hline Item name & Item contents \\
\hline Type of conductor & JL/G1A-630/45-45/7 \\
\hline Name of conductor & $\begin{array}{c}\text { Aluminium conductor } \\
\text { steel reinforced }\end{array}$ \\
\hline $\begin{array}{c}\text { Strand number/diameter of } \\
\text { aluminium single wire (piece/mm) }\end{array}$ & $45 / 4.22$ \\
\hline $\begin{array}{c}\text { Strand number/diameter of } \\
\text { galvanized steel wire }(\text { piece } / \mathrm{mm})\end{array}$ & $7 / 2.81$ \\
\hline $\begin{array}{c}\text { Sectional area of conductor }\left(\mathrm{mm}{ }^{2}\right) \\
\text { Outer diameter }(\mathrm{mm})\end{array}$ & 674.0 \\
\hline Rated tensile force $(\mathrm{kN})$ & 33.8 \\
\hline Elastic module of conductor $(\mathrm{GPa})$ & 6150.45 \\
\hline $\begin{array}{c}\text { Thermal expansion coefficient of } \\
\text { conductor }\left(10^{-6} /{ }^{\circ} \mathrm{C}\right)\end{array}$ & $20.9 \times 10^{-6}$ \\
\hline DC resistance at $20^{\circ} \mathrm{C}(\Omega / \mathrm{km})$ & $\leq 0.0459$ \\
\hline
\end{tabular}
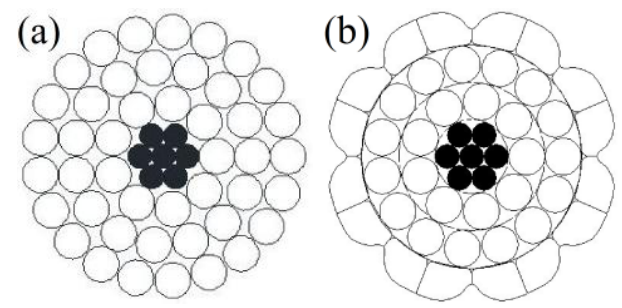

(c)

(d)
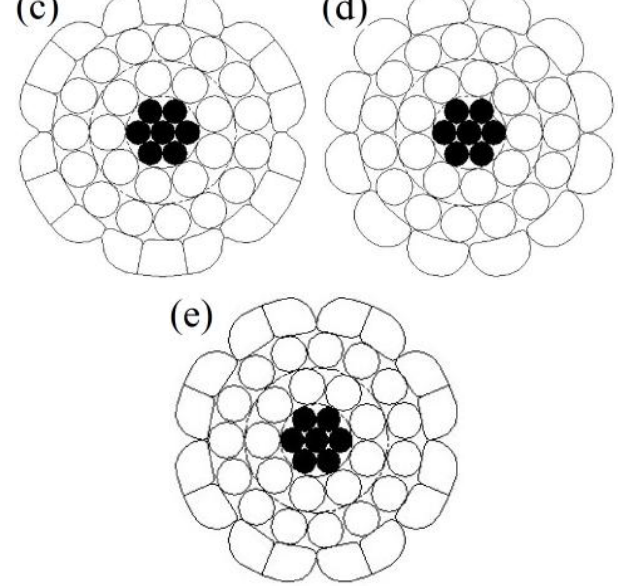

Figure 1. Schematic sections of the conventional conductor and four designed drag reduced conductors: (a) conventional conductor JL/G1A-630/45-45/7, (b) DFY630/45(45 ${ }^{\circ}$-R3.5, (c) DFY630/45(60 $\left.{ }^{\circ}\right)-\mathrm{R} 3.5$, (d) DFY630/45(45 $)$-R3.2 and (e) DFY630/45(60 $)-\mathrm{R} 3.2$. 


\section{Wind tunnel test results and discussion}

In order to investigate the wind load reducing effect of drag reduced conductors, wind tunnel test was carried out to obtain the wind resistance coefficient in unit length. The wind tunnel test was completed in the low speed aerodynamics lab of China Aerodynamics Research and Development Centre. The size of test section was 1.4 $\mathrm{m} \times 1.4 \mathrm{~m} \times 2.8 \mathrm{~m}$, and continuous wind speed at 10 70 $\mathrm{m} / \mathrm{s}$ can be generated in the wind tunnel. Considering the wind speed range in strong wind areas, six wind speed scales including $20 \mathrm{~m} / \mathrm{s}, 30 \mathrm{~m} / \mathrm{s}, 40 \mathrm{~m} / \mathrm{s}, 50 \mathrm{~m} / \mathrm{s}, 60 \mathrm{~m} / \mathrm{s}$ and $70 \mathrm{~m} / \mathrm{s}$ were employed in the test. During testing, the data collection frequency of the force measurement balance was $1000 \mathrm{~Hz}$ and the collecting time was $1 \mathrm{~min}$. Figure 2 shows the arrangement of conductor samples during wind tunnel testing. Two working conditions including the angle between the conductor and the incoming flow at $90^{\circ}$ and $60^{\circ}$ were considered.

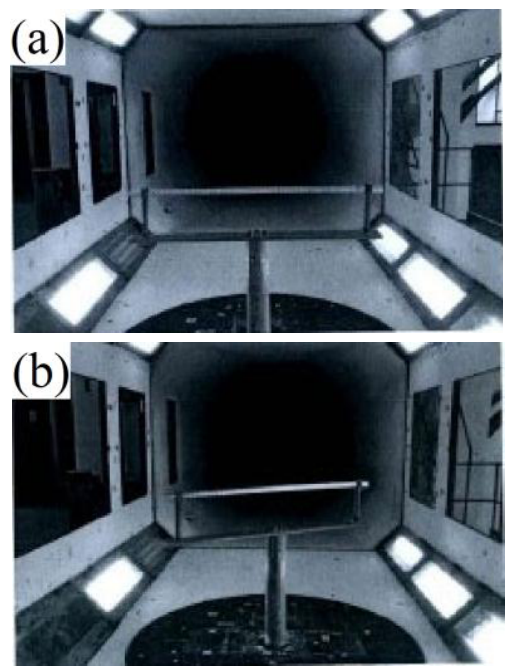

Figure 2. Arrangement of conductor samples during wind tunnel testing: (a) angle between conductor and incoming flow was $90^{\circ}$ and (b) angle between conductor and incoming flow was $60^{\circ}$.

The wind resistance coefficient in unit length of the conductor can be calculated by the following equation [5]:

$$
C_{d}=\frac{F_{d}}{\frac{1}{2} \rho u^{2} L d}
$$

where $C_{d}$ represents wind resistance coefficient in unit length of the conductor, $F_{d}$ represents wind resistance of the conductor $(\mathrm{N}), \rho$ represents air density $\left(\mathrm{kg} / \mathrm{m}^{3}\right), \mathrm{u}$ represents wind speed $(\mathrm{m} / \mathrm{s})$, L represents length of the conductor $(\mathrm{m})$ and $\mathrm{d}$ represents diameter of the conductor (m). The value of $F_{d}$ can be directly measured by the force measurement balance. Introduce the value of $F_{d}$ and other parameters into equation (1) and the value of $\mathrm{C}_{\mathrm{d}}$ can be obtained. Table 2 and table 3 list the calculation results, in which $1 \#$ represents the conventional conductor JL/G1A-630/45-45/7, 2\# represents the drag reduced conductor DFY630/45(45 $)$-R3.5, 3\# represents the drag reduced conductor DFY630/45(60 $)$-R3.5, 4\# represents the drag reduced conductor DFY630/45(45)R3.2 and 5\# represents the drag reduced conductor DFY630/45(60)-R3.2. Figure 3 shows the corresponding relationship curves between the wind resistance coefficient in unit length of the conductor and the wind speed. In can be seen from the figure that the wind resistance coefficients in unit length of four drag reduced conductors were obviously lower than that of the conventional conductor when the wind speed was larger than $30 \mathrm{~m} / \mathrm{s}$. This indicates that the slotting way on the outside surface of the conductors with round section significantly decreased the wind load withstood by the conductors and the wind load reducing effect was more obvious under strong wind conditions. Furthermore, it can also be seen from the figure that the wind resistance coefficients in unit length of four drag reduced conductors were close to each other, but slight difference also existed. Among the conductors, DFY630/45(45 ${ }^{\circ}$ R3.2 showed the lowest wind resistance coefficient in unit length, followed by DFY630/45(60)-R3.2. This suggests that the wind load reducing effect of the conductor became more obvious with the reduction of open angle and arc radius of the outside surface of the conductor.

\section{Manufacturing process of drag reduced conductors}

The manufacturing process of the drag reduced conductor is basically consistent with that of the conventional conductor, which mainly includes aluminium ingot melting, insulating, casting, continuous rolling, wire drawing, wire twisting, packaging and transporting. But as compared to the conventional conductor, the following key points should be noted during manufacturing process of the drag reduced conductor:

(1) High-quality aluminium ingots should be used as raw materials and the composition of aluminium liquid should be effectively controlled by trace element treatment technology to guarantee the tensile strength and resistance rate of aluminium wires.

(2) Strengthen uniformity of aluminium wires should be effectively controlled by keeping aluminium liquid temperature uniform during continuous casting and rolling process, and emulsification liquid should be employed in the climbing pipe to eliminate self-annealing effect.

(3) Impurity level of aluminium wires should be effectively controlled. High-efficient and nontoxic refinery agent should be employed to remove hydrogen and alumina impurities in the aluminium liquid, and ceramic filter board should be placed in the casting drum to remove the slag in the aluminium liquid during casting process.

(4) Quality of wire drawing should be effectively controlled. High-quality wire drawing oil should be applied to guarantee the cleanness and surface quality of aluminium wires, and polycrystalline mould should be applied to improve production efficiency and guarantee product quality. 
Table 2. Wind resistance coefficients in unit length of conductors under different wind speeds (angle between conductor and incoming flow was $90^{\circ}$ )

\begin{tabular}{|c|c|c|c|c|c|}
\hline $\begin{array}{c}\text { Wind speed } \\
(\mathrm{m} / \mathrm{s})\end{array}$ & $1 \#$ & $2 \#$ & $3 \#$ & $4 \#$ & $5 \#$ \\
\hline 20 & 0.98386 & 1.12814 & 1.07772 & 1.08130 & 1.08941 \\
\hline 30 & 1.06949 & 0.94017 & 0.95439 & 0.93193 & 0.90630 \\
\hline 40 & 0.94393 & 0.81939 & 0.84519 & 0.82518 & 0.83458 \\
\hline 50 & 0.98091 & 0.87536 & 0.90226 & 0.83663 & 0.88052 \\
\hline 60 & 0.96887 & 0.89281 & 0.90255 & 0.85423 & 0.86761 \\
\hline 70 & 0.99009 & 0.90991 & 0.92066 & 0.87914 & 0.88313 \\
\hline
\end{tabular}

Table 3. Wind resistance coefficients in unit length of conductors under different wind speeds (angle between conductor and incoming flow was $60^{\circ}$ )

\begin{tabular}{|c|c|c|c|c|c|}
\hline $\begin{array}{c}\text { Wind speed } \\
(\mathrm{m} / \mathrm{s})\end{array}$ & $1 \#$ & $2 \#$ & $3 \#$ & $4 \#$ & $5 \#$ \\
\hline 20 & 0.62228 & 0.57902 & 0.56156 & 0.62025 & 0.52541 \\
\hline 30 & 0.64171 & 0.62129 & 0.62112 & 0.58154 & 0.57319 \\
\hline 40 & 0.64860 & 0.58368 & 0.59606 & 0.57329 & 0.59369 \\
\hline 50 & 0.66019 & 0.59569 & 0.62192 & 0.56689 & 0.61654 \\
\hline 60 & 0.62887 & 0.61036 & 0.61578 & 0.56229 & 0.60266 \\
\hline 70 & 0.65989 & 0.63868 & 0.62902 & 0.56640 & 0.62348 \\
\hline
\end{tabular}
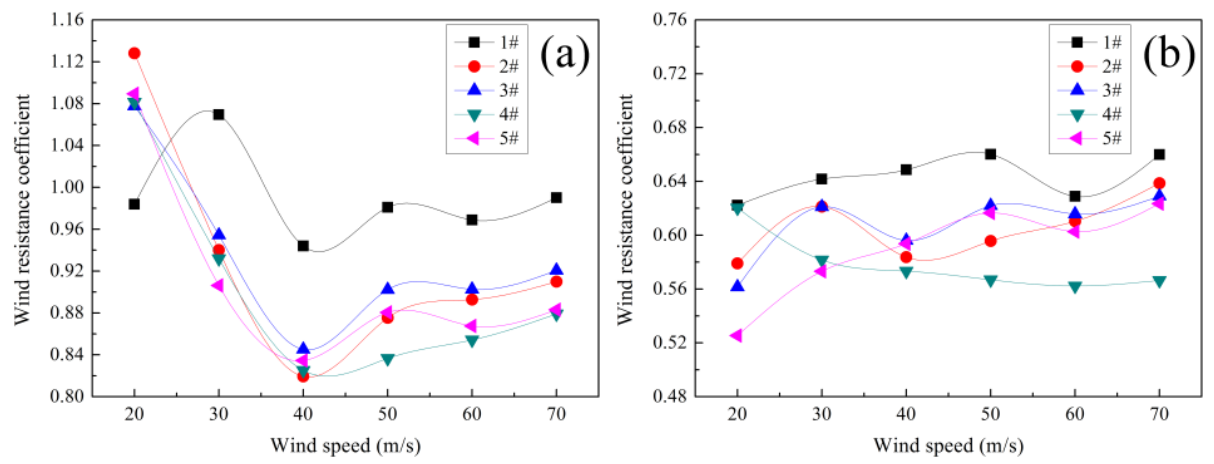

Figure 3. Relationship curves between wind resistance coefficient in unit length of conductors and wind speed: (a) angle between conductor and incoming flow was $90^{\circ}$ and (b) angle between conductor and incoming flow was $60^{\circ}$.

(5) The pre-twisted device and the wire tension adjustment device should be reasonably designed to guarantee twisting quality of conductors.

\section{Conclusions}

In this paper, four drag reduced conductors were designed based on the structure optimization of the conventional aluminium conductor steel reinforced. The wind tunnel test was performed and the manufacturing process of drag reduced conductors was analyzed. Conclusions can be drawn as follows:

(1) The wind resistance coefficients in unit length of four drag reduced conductors were obviously lower than the conventional conductor. The slotting way on the outside surface of the conductors with round section 
significantly decreased the wind load withstood by the conductor.

(2) The reducing effect of wind load was related to opening angle and arc radius of the outside surface of the conductor.

(3) The manufacturing process of drag reduced conductors was basically consistent with the conventional conductor. And the popularization and application of drag reduced conductors for electric power transmission lines in strong wind areas can be realized by finely controlling the manufacturing process to guarantee product quality.

\section{References}

1. D.Y. Kong, L. Li, X.H. Long, Z.P. Liang, Journal of Vibration and Shock 26, 64 (2007)

2. C.Y. You, Electric Power Construction 31, 1 (2010)

3. S. Zheno, Sumitomo electrics 122, 61 (1983)

4. C.Y. You, Electric Power Construction 26, 1 (2005)

5. P.Dang, X.M. Wu, B. Liu, L. Wang, W. Zeng, Q. Zheng, C.H. Li, Electric Wire \& Cable 4, 30 (2014) 